\title{
Interfacial geometry dependence of the iron magnetic moment: The case of $\mathrm{MgO} / \mathrm{Fe} / \mathrm{MgO}$
}

\author{
Juan Ignacio Beltrán, ${ }^{1, *}$ Lluis Balcells, ${ }^{2}$ and Carlos Martínez-Boubeta ${ }^{3}$ \\ ${ }^{1}$ Departamento de Física Teórica de la Materia Condensada, Universidad Autónoma de Madrid, Madrid 28049, Spain \\ ${ }^{2}$ Instituto de Ciencia de Materiales de Barcelona (ICMAB-CSIC), Campus UAB, Bellaterra 08193, Spain \\ ${ }^{3}$ Departament d'Electrònica and IN2UB, Universitat de Barcelona, Barcelona 08028, Spain
}

(Received 23 September 2011; revised manuscript received 9 December 2011; published 27 February 2012)

\begin{abstract}
The prediction and experimental demonstration of a very large magnetoresistance in $\mathrm{Fe} / \mathrm{MgO} / \mathrm{Fe}$ tunnel junctions have led to intense study of related systems in the last decade. In the present paper, we concentrate on the role of interface coordination, Fe thickness, and magnetization in the $\mathrm{MgO} / \mathrm{Fe} / \mathrm{MgO}$ mirror. By first-principles analysis, it is shown that the iron magnetic moment can rise up to $4 \mu_{\mathrm{B}}$, accounting for observed deviation of the $\mathrm{Fe}$ atoms in the vicinity of $\mathrm{MgO}$ interfaces. The origin is attributed to site preference predicted by our calculations, namely, that, unlike the case of Fe atoms in the monolayer range sitting just above the oxygen atoms of the $\mathrm{MgO}(001)$ substrate, the charge transfer induced by the $\mathrm{O} p-d \mathrm{Fe}$ interaction leads to a structural distortion that stabilizes the $\mathrm{Mg}$ at the very first deposition stages of the capping layer, facing Fe sites.
\end{abstract}

DOI: 10.1103/PhysRevB.85.064417

PACS number(s): 75.70.-i, 75.40.Mg, 75.50.Bb

\section{INTRODUCTION}

The ability to control both the atomic structure and composition of hetero-interfaces is emerging as one of the major challenges for the development of novel electronic devices with a range of functional properties. In this regard, previous studies reported ${ }^{1,2}$ that the preferential tunneling of $\Delta_{1}$ symmetry states in $\mathrm{Fe} / \mathrm{MgO} / \mathrm{Fe}(001)$ junctions would lead to magnetoresistance values in excess of $1000 \%$. Such a huge value has not yet been obtained, but the tunneling magnetoresistance has gradually been increasing since then. ${ }^{3-5}$ Progress made in the last decade is the result of the study not only of the transport properties but a continuous effort in characterizing the $\mathrm{MgO}$ crystalline barrier, the chemical composition of the interface, and its electronic structure, which provide information on the spin polarization of the system. ${ }^{6-10}$ Yet, the nature of $\mathrm{Fe}$ at the $\mathrm{MgO}$ interface, with differences between the $\mathrm{Fe} / \mathrm{MgO}$ and $\mathrm{MgO} / \mathrm{Fe}$ cases in real systems, ${ }^{11}$ is still under debate. For instance, one of the major consequences of the deposition of $\mathrm{MgO}$ on a metal surface is a shift in the metal work function. ${ }^{12-14}$ This metal-supported $\mathrm{MgO}$ barrier (such is the case for $\mathrm{Fe} / \mathrm{MgO}$ ) shows modified wetting properties, which can influence the structure and magnetization of the posterior $\mathrm{Fe}$ atoms deposited on top (thus modifying the $\mathrm{Fe} / \mathrm{MgO} / \mathrm{Fe}$ nominal symmetry). ${ }^{15,16}$ Accordingly, as theoretically predicted, ${ }^{17}$ the surface magnetism would be enhanced by about $30 \%$ compared with the bulk magnetic moment ( $\mathrm{mm}$ ) of $2.2 \mu_{\mathrm{B}}$. From an experimental point of view, Koyano et al. ${ }^{18}$ confirmed the enhanced $\mathrm{mm}$ of the lattice-distorted $\mathrm{Fe}$ in polycrystalline $\mathrm{Fe} / \mathrm{MgO}$ multilayered films. More recently, Sicot et al. ${ }^{19}$ studied the electronic and magnetic properties of $\mathrm{Fe}$ epitaxial monolayers (ML) in contact with a singlecrystalline $\mathrm{MgO}(001)$ tunneling barrier using $\mathrm{x}$-ray absorption spectroscopy and x-ray magnetic circular dichroism (XMCD) measurements. They tried to definitely demonstrate the enhancement of the Fe $\mathrm{mm}$ in contact with $\mathrm{MgO}$ by performing measurements on samples with the following architecture (from the substrate side): V(001) buffer/10 ML Co-bcc/1 ML $\mathrm{Fe} / \mathrm{MgO}$. Similar experiments were performed by Mamiya et $a l .{ }^{20}$ Values reach $3.0 \pm 0.3 \mu_{\mathrm{B}}$ per Fe atom at room temperature (RT). So far, however, it has been difficult to separate the different contributions of $\mathrm{Co}$ and $\mathrm{MgO}$ in the enhancement of the $\mathrm{mm}$. These observations also provided evidence that the $1 \mathrm{ML}$ Fe supported onto a metal ( $\mathrm{Co}$ ) is not oxidized at all, despite the Fe layer directly facing the $\mathrm{MgO}$ barrier. However, this argument may not apply for the case of $\mathrm{Fe}$ deposited onto $\mathrm{MgO}$, given the importance to consider the actual charge transfer between Fe atoms and their surroundings, ${ }^{14}$ as discussed above. Indeed, electronic mixing ${ }^{17,21}$ and evidences for a $\mathrm{FeO}$ interface have been demonstrated but credited to be due to thermodynamic constraints. ${ }^{22,23}$

Little attention has been given to the properties of the $\mathrm{MgO} / \mathrm{Fe} / \mathrm{MgO}$ system. In this paper, the effect of interfacial coordination on the structural and magnetic properties of $\mathrm{Fe}$ sandwiches is investigated via first-principles calculations. In agreement with experiments, a magnetic moment much higher than the bulk is demonstrated, which we expect to play an important role in the study of double tunnel junctions and samples exhibiting quantum confinement effects. ${ }^{24,25}$

\section{EXPERIMENT AND MODEL}

We first measured the $\mathrm{mm}$ of ultrathin Fe films sandwiched between $\mathrm{MgO}$ layers in fully epitaxial (001) oriented structures consisting of a $\mathrm{MgO}(001)$ substrate/MgO (10 $\mathrm{nm}$ buffer)/Fe/MgO (10 nm capping). Details have been previously described. ${ }^{26}$ Briefly, experiments were conducted on sputtered films deposited at RT in order to avoid threedimensional island growth and minimize interdiffusion. The thickness of the Fe layer was accurately determined by measuring the $\mathrm{X}$-ray reflectivity. This technique has been proven to be especially sensitive in the case of symmetric structures, where the deposition of alternating layers of high $(\mathrm{Fe})$ and low refractive index $(\mathrm{MgO})$ creates interference fringes and drastic changes in the reflectivity, thus allowing for single-atomiclayer resolution. Magnetization was measured using available commercial superconducting quantum interference devices (SQUID) at RT and with a maximum magnetic field of $55 \mathrm{kOe}$ applied parallel to the film plane. In all cases, the linear diamagnetic background from the $\mathrm{MgO}$ substrate and capping layers has been properly subtracted. ${ }^{27}$ In Fig. 1, we present the plot 


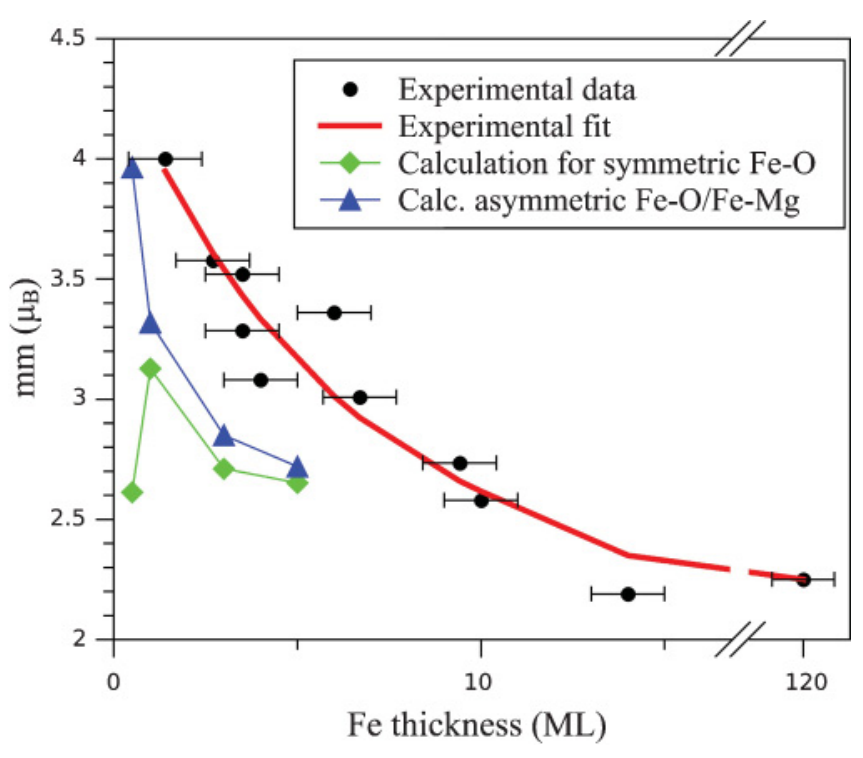

FIG. 1. (Color online) Magnetic moment averaged per Fe atom from SQUID measurements (black circles), together with theoretical calculations of $\mathrm{MgO} / \mathrm{Fe} / \mathrm{MgO}$ structures with symmetric $\mathrm{Fe}-\mathrm{O}$ bonding (green diamonds), and asymmetric coordination (blue triangles), as a function of the Fe thickness. The experimental data are fitted to a phenomenological exponential decaying function (as $\mathrm{mm}=\mathrm{mm}_{\text {bulk }}+\mathrm{mm}_{\text {surface }} e^{[1-\text { thicknes }] / k}$, with the characteristic decay length $k=6 \mathrm{ML}$ ), which converge at large coverage to bulk Fe values.

of the experimental $\mathrm{mm}$ at saturation, averaged per $\mathrm{Fe}$ atom, as a function of the Fe layer width, together with simulations of two different $\mathrm{MgO}$ (substrate) $/ \mathrm{Fe} / \mathrm{MgO}$ (capping) geometrical arrangements (see following). We find that $\mathrm{mm}$ is larger than the bulk value for the thinner films and monotonically decays with film thickness. Thus, it seems clear that a genuine surface $\mathrm{mm}$ enhancement is seen. It reaches about $4 \mu_{\mathrm{B}}$, thus either indicating the valence state of iron to be closer to $\mathrm{Fe}^{2+}$, as for the case of diluted iron impurities in $\mathrm{MgO}^{28}$ or the $\mathrm{Fe}$ atom to be bounded to $\mathrm{Mg}$ ions. ${ }^{29}$ We should note that XMCD experiments in our samples ${ }^{30}$ showed neither $\mathrm{mm}$ induced on the $\mathrm{MgO}$ due to the proximity of the ferromagnet, nor a multiplet structure indicative of iron oxidation. We surmise the answer to this dilemma depends on a complex interplay between the structural changes and the charge-transfer process at the interface.

We next used the semilocal density functional theory to investigate the magnetic properties of Fe layers facing $\mathrm{MgO}$. Calculations were performed at the generalized-gradient approximation level, using the exchange-correlation functional developed by Perdew, Burke, and Ernzerhof. ${ }^{31}$ We employed the SIESTA code with its localized atomic orbital basis sets. ${ }^{32}$ Global structure optimization included a $6 \times 6 \times 6 k$-point mesh and an energy cutoff value of $300 \mathrm{Ry}$. The atoms within the supercell are relaxed by using a conjugate gradient minimization until the atomic forces are less than $0.1 \mathrm{eV} / \AA$. The settings of the calculation are described elsewhere. ${ }^{33}$ Special attention was given to the thickness of the slab representing the $\mathrm{MgO}$ substrate and Fe layers, which have been shown to profoundly affect the calculated magnetic properties. ${ }^{34}$ We have
TABLE I. Magnetic moment (mm) projected to the interfacial Fe and $\mathrm{O}$ ions in various slab structures. The stability of each system is expressed with respect to the total energy of the isolated constituents.

\begin{tabular}{|c|c|c|c|c|c|c|}
\hline & \multicolumn{2}{|c|}{$\begin{array}{c}\text { Layers } \\
\text { (ML) }\end{array}$} & \multicolumn{2}{|c|}{$\mathrm{mm}\left(\mu_{\mathrm{B}}\right)$} & \multirow{2}{*}{$\begin{array}{c}\text { Distance }(\AA) \\
\text { Fe-O }\end{array}$} & \multirow{2}{*}{$\begin{array}{c}\text { Stability } \\
(\mathrm{eV})\end{array}$} \\
\hline & $\mathrm{MgO}$ & $\mathrm{Fe}$ & $\mathrm{Fe}$ & $\mathrm{O}$ & & \\
\hline \multirow[t]{11}{*}{ Superlattice } & 4 & 0.5 & 3.41 & 0.14 & 1.96 & 4.70 \\
\hline & & 1 & 3.23 & 0.09 & 2.05 & 3.26 \\
\hline & 5 & 0.5 & 3.10 & 0.03 & 2.14 & 2.83 \\
\hline & & 1 & 3.31 & 0.05 & 2.30 & 1.41 \\
\hline & & 2 & 2.76 & 0.04 & 2.09 & 1.37 \\
\hline & & 3 & 2.71 & 0.04 & 2.07 & -1.38 \\
\hline & & 5 & 2.68 & 0.07 & 2.02 & -1.65 \\
\hline & 6 & 0.5 & 3.51 & 0.15 & 1.95 & 3.48 \\
\hline & & 1 & 3.33 & 0.07 & 2.13 & 3.28 \\
\hline & 7 & 0.5 & 2.98 & 0.01 & 2.11 & 2.50 \\
\hline & & 1 & 3.30 & 0.05 & 2.31 & 1.32 \\
\hline \multirow[t]{9}{*}{ Thin film } & 4 & 0.5 & 3.94 & 0.11 & 2.06 & 4.15 \\
\hline & & 1 & 3.46 & 0.06 & 2.15 & 3.45 \\
\hline & 5 & 0.5 & 4.01 & 0.10 & 2.06 & 3.88 \\
\hline & & 1 & 3.42 & 0.06 & 2.14 & 3.47 \\
\hline & & 2 & 2.75 & 0.04 & 2.06 & 2.36 \\
\hline & & 3 & 2.88 & 0.06 & 2.05 & 3.00 \\
\hline & & 5 & 2.84 & 0.05 & 2.05 & 3.19 \\
\hline & 6 & 0.5 & 4.01 & 0.10 & 2.06 & 3.89 \\
\hline & & 1 & 3.40 & 0.06 & 2.13 & 3.42 \\
\hline
\end{tabular}

considered Fe coverages down to $0.5 \mathrm{ML}$, since in real samples, the interface cannot be perfectly flat (the $\mathrm{MgO}$ substrate steps being intrinsically higher than an Fe ML). ${ }^{26}$ Two different slab structures were designed: a periodic thin film configuration separated by $15 \AA$ of vacuum, and superlattice arrangements. By changing the barrier width, we aimed to quantify the relative importance of the coordination determining the $\mathrm{mm}$ : superlattice structures with an even number of $\mathrm{MgO}$ monolayers consist of stacked layers alternating between those that contain only $\mathrm{Fe}$ atoms placed atop $\mathrm{O}$ atoms $(\mathrm{Fe}-\mathrm{O})$, consistent with the experimental data, ${ }^{35,36}$ and those in which the $\mathrm{Fe}$ is forced to bind to $\mathrm{Mg}(\mathrm{Fe}-\mathrm{Mg})$. In contrast, for an odd number of $\mathrm{MgO}$ layers, the $\mathrm{O}$ interfacial ions always face the $\mathrm{Fe}$ atoms while $\mathrm{Mg}$ falls in hollow positions. Results showed substantial energy differences between different types of structures. For the superlattice, the different coordination affects each of the properties in Table I. Namely, stability is larger for an odd number of $\mathrm{MgO}$ layers, which implies that the Fe is preferentially located on the oxygen on-top site. However, in the thin film structure, there is no qualitative difference among the $\mathrm{MgO}$ coverage ranges. This is a result of the interface always being $\mathrm{Fe}-\mathrm{O}$ coordinated and the interaction between the periodically repeated slabs being decoupled by the introduction of vacuum. Notably, we found good agreement of our $\mathrm{mm}$ values with earlier calculations for supported $\mathrm{Fe}$ layers or clusters onto $\mathrm{MgO} .{ }^{16,17,37,38}$ For thicker Fe films, compensation of interface charge by the shallow Fe layers gradually decreases the enhancement of the surface magnetization towards the bulk Fe value. 
(a)

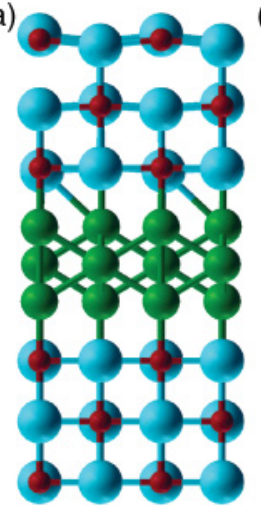

(b)

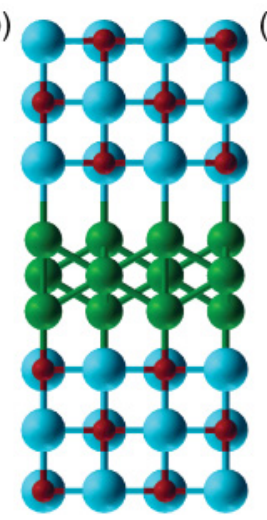

(c)

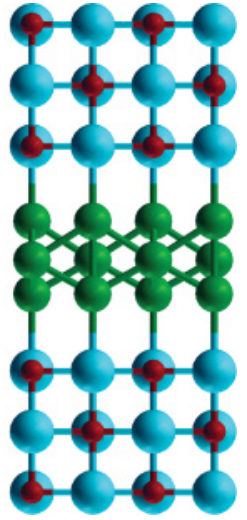

FIG. 2. (Color online) Schematics, from bottom to top, of the calculated crystalline structure for the $\mathrm{MgO}$ (substrate) $/ \mathrm{Fe} / \mathrm{MgO}$ (capping) case with $3 \mathrm{ML} \mathrm{Fe}$ facing oxygen ions at both interfaces (a), Fe binds to the $\mathrm{O}$ ions onto the substrate but to $\mathrm{Mg}$ in the capping layer (b), and $\mathrm{Fe}$ facing $\mathrm{Mg}$ at both sides (c). Small (red), big (blue), and medium (green) circles correspond to $\mathrm{O}, \mathrm{Mg}$, and $\mathrm{Fe}$, respectively.

The interatomic distances along the out-of-plane (001) direction are also summarized in Table I. The interfacial $\mathrm{Fe}-\mathrm{O}$ distances are found to be shorter than the distance in bulk $\mathrm{FeO}(2.154 \AA) .{ }^{39}$ Small mm oscillations in varying $\mathrm{Fe}$ and $\mathrm{MgO}$ thickness are also clearly illustrated. Curiously, spin-dependent electron reflectivity and the work function of the $\mathrm{MgO}$ thin films grown on $\mathrm{Fe}(001)$ have also been demonstrated to oscillate with $\mathrm{MgO}$ thickness. ${ }^{40}$ We have, therefore, investigated the effect of interfacial chemical structure using $\mathrm{MgO} / \mathrm{Fe} / \mathrm{MgO}$ sandwiches. Three structures were considered: Fe facing oxygen ions at both the $\mathrm{MgO} / \mathrm{Fe}$ and $\mathrm{Fe} / \mathrm{MgO}$ interfaces (called hereafter "symmetric $\mathrm{Fe}-\mathrm{O}$ "), $\mathrm{Fe}$ binds to the $\mathrm{O}$ ions onto the substrate but to $\mathrm{Mg}$ in the capping layer ("asymmetric Fe-Mg"), and Fe facing $\mathrm{Mg}$ at both sides

(referred to as "symmetric Fe-Mg"). The (001) in-plane $\mathrm{MgO}$ substrate lattice was fixed at the bulk value (optimized lattice parameter $4.27 \AA$ ), and the $\mathrm{Fe}$ and capping layers were matched epitaxially, as shown in Fig. 2.

For some of the configurations in Fig. 2, we show in Fig. 1 the $\mathrm{mm}$ as a function of the Fe layer width. The $\mathrm{mm}$ is large for the thin film structures and decays monotonically, showing a maximum for the smallest coverage, except for the symmetric $\mathrm{Fe}-\mathrm{O}$ case. This situation arises because the interfacial properties are mostly driven by the $\mathrm{Fe}-\mathrm{O}$ charge transfer, $\mathrm{Fe}$ being the electron donor and $\mathrm{O}$ being the acceptor, which is not full due to the reduced Fe coverage. The (non-)decaying trend corresponds to the Fe coverage that decreases (increases) the $\mathrm{Fe}$ averaged amount of electrons transferred to the $\mathrm{O}$. Therefore, the maximum in Fig. 1 can be regarded as a compromise between an increase of $\mathrm{mm}$ due to ionicity and a decrease by the bulk-like character of thicker Fe coverages.

\section{DISCUSSION AND CONCLUSION}

We considered structural relaxations to account for the electronic response to the epitaxial in-plane strain. However, we could not find remarkable differences in magnetic moments among the relaxed and unrelaxed structures, suggesting the surface relaxation, and thus change in interlayer distance, only slightly contributes to the enhancement of magnetic moment, as already reported in Ref. 41 . Figure 2 gives evidence for the oscillating relaxation and rumpling obtained for $\mathrm{Fe} / \mathrm{MgO}$ (capping) in this procedure. ${ }^{42}$ Such rumpling mostly takes place in the $\mathrm{Fe}-\mathrm{O}$ coordination, rather than in the $\mathrm{Fe}-\mathrm{Mg}$, and it is related to the interfacial charge transfer. This can be seen in Table II since the amount of $\mathrm{O}$ charge is clearly larger at the interfaces with $\mathrm{Fe}-\mathrm{O}$ coordination. In fact, the structural distorsion in the oxide film creates a dipole moment which partially compensates that due to the interfacial charge transfer. Note that there is almost no difference in the $\mathrm{mm}$ values for

TABLE II. Mulliken charges projected to the atoms of the $\mathrm{MgO}$ (substrate)|Fe and $\mathrm{Fe} \mid \mathrm{MgO}$ (capping) interfaces for different Fe coverages, with the $\mathrm{MgO}$ thickness fixed to $3 \mathrm{ML}$. We also include the average magnetic moment per iron (mm), and stability of the $\mathrm{MgO} / \mathrm{Fe} / \mathrm{MgO}$ heterostructure regarding the constituent crystals.

\begin{tabular}{|c|c|c|c|c|c|c|c|}
\hline & \multirow{2}{*}{$\begin{array}{l}\mathrm{Fe} \\
\mathrm{ML}\end{array}$} & \multicolumn{2}{|c|}{$\mathrm{MgO} \mid \mathrm{Fe}$} & \multicolumn{2}{|c|}{$\mathrm{Fe} \mid \mathrm{MgO}$} & \multirow{2}{*}{$\begin{array}{l}\mathrm{mm} \\
\left(\mu_{\mathrm{B}}\right)\end{array}$} & \multirow{2}{*}{$\begin{array}{c}\text { Stability } \\
(\mathrm{eV})\end{array}$} \\
\hline & & $\mathrm{O}$ & $\mathrm{Fe}$ & $\mathrm{Fe}$ & $\mathrm{O}$ & & \\
\hline \multirow[t]{4}{*}{ Symmetric Fe-O } & 0.5 & $6.79 / 6.69$ & 7.36 & 7.36 & $6.71 / 6.79$ & 2.61 & 6.68 \\
\hline & 1 & 6.77 & 7.29 & 7.29 & 6.77 & 3.13 & 6.88 \\
\hline & 3 & 6.81 & 7.66 & 7.66 & 6.82 & 2.71 & 10.15 \\
\hline & 5 & 6.82 & 7.66 & 7.67 & 6.82 & 2.65 & 15.94 \\
\hline \multirow[t]{6}{*}{ Asymmetric Fe-Mg } & 0.5 & $6.67 / 6.68$ & 7.34 & 7.34 & $6.70 / 6.80$ & 3.96 & 7.41 \\
\hline & 1 & 6.80 & 7.46 & 7.46 & 6.66 & 3.32 & 9.06 \\
\hline & 3 & 6.82 & 7.70 & 7.85 & 6.67 & 2.84 & 12.72 \\
\hline & 5 & 6.82 & 7.63 & 7.79 & 6.67 & 2.72 & 18.99 \\
\hline & 8 & 6.82 & 7.64 & 7.90 & 6.69 & 2.74 & 30.77 \\
\hline & 10 & 6.82 & 7.64 & 7.88 & 6.68 & 2.74 & 37.94 \\
\hline \multirow[t]{4}{*}{ Symmetric Fe-Mg } & 0.5 & 6.69 & 7.46 & 7.46 & 6.69 & 3.99 & 8.51 \\
\hline & 1 & 6.67 & 7.66 & 7.66 & 6.67 & 3.40 & 10.60 \\
\hline & 3 & 6.82 & 7.71 & 7.84 & 6.67 & 2.85 & 12.73 \\
\hline & 5 & 6.67 & 7.80 & 7.79 & 6.67 & 2.78 & 22.22 \\
\hline
\end{tabular}


thicker Fe coverages (5, 8, and $10 \mathrm{ML})$. This saturation value, different from the experimental Fe bulk value of $2.26 \mu_{\mathrm{B}}$, is due to the interfacial constraints imposed onto the in-plane lattice parameter matching that of the $\mathrm{MgO}$ substrate. This leads to an Fe cell dimension of $3.02 \AA$, instead of the $2.87 \AA$ lattice constant of a body-centered cubic iron. We assessed accuracy of the computational method by conducting a series of calculations on Fe bulk. The optimum lattice constant of $\mathrm{Fe}$ bulk was calculated to be $2.87 \AA$, with a magnetic moment of $2.34 \mu_{\mathrm{B}}$. Accordingly, calculations in unsupported Fe crystals with a cell dimension of $3.02 \AA$ indicated that $\mathrm{mm}$ increases up to $2.71 \mu_{\mathrm{B}}$. Thus, these results give us some confidence in the validity of our model for the case of Fe ultrathin distorted films grown epitaxially onto substrates.

Regarding epitaxial stability, a summary of the total energy for each of the interface coordinations is shown in Table II. One can clearly see that the "symmetric Fe-O" coordination is more stable than any of the Fe-Mg ones. However, the stability difference between the "symmetric Fe-O" and "asymmetric $\mathrm{Fe}-\mathrm{Mg}$ " increases by increasing the Fe coverage, being only about $0.7 \mathrm{eV}$ for the $0.5 \mathrm{Fe} \mathrm{ML}$ case. Besides, we have calculated the total energy for intermediate 1 and $2 \mathrm{ML} \mathrm{MgO}$ cappings, which have stability values of 7.72 and $6.88 \mathrm{eV}$ for the "symmetric Fe-O," while values are 6.77 and 7.55 $\mathrm{eV}$ for the "asymmetric Fe-Mg." Importantly, this indicates that the most stable location for the magnesium atoms is on top of $\mathrm{Fe}$ for the first $\mathrm{MgO}$ layer. The reasons underlying the Fe-Mg stability, however, still remain open. Whereas the parameter of interest is often the optimal interface separation for which the total energy is minimal, one needs to remember that at a realistic interface, significant numbers of atoms are located off their preferential adsorption site and/or at distances different from those estimated in model calculations, as already pointed out for the $\mathrm{Mo}(001) / \mathrm{MgO}$ case. ${ }^{43}$ In-situ scanning tunneling microscopy would be highly valuable to confirm this point. For instance, studies on two-dimensional Fe islands onto $\mathrm{MgO}(001)$ demonstrated that hardly any atom is occupying the energetically most favorable fourfold hollow sites of the bcc lattice, ${ }^{44}$ where the majority of atoms are displaced to less favorable sites, which might facilitate $\mathrm{Fe}$ above $\mathrm{Mg}$ ions. In addition, $a b$ initio studies also confirmed that the adsorption energy of $\mathrm{Fe}$ at oxygen-defect sites, with four nearest $\mathrm{Mg}$ neighbors, is slightly lower than that of $\mathrm{Fe}$ on top of the surface $\mathrm{O}$ atom of stoichiometric $\mathrm{MgO}(001) .{ }^{45}$ It is also worth mentioning that the metallic $\mathrm{Mg}$ insertion layer between the $\mathrm{MgO}$ barrier and a bottom magnetic layer is known to be efficient for increasing the magnetoresistance ratio and for reducing the device resistance area product. ${ }^{46}$ We note that changes in the $\mathrm{MgO}$ barrier as a function of high-temperature annealing (an indispensable step to obtain giant tunneling magnetoresistance above $100 \%$ in $\mathrm{MgO}$-based junctions) have been extensively studied. Annealing is found to decrease the resistance of the junction, although the effective barrier layer width expands. ${ }^{47}$ This paradox is usually explained as being due to a reduction of the density of oxygen vacancies, though the resulting similarities with the $\mathrm{Mg}$ insertion layer case might point to their common origin. Please note that $\mathrm{Mg}$ can diffuse easily at the temperatures involved here, producing a $\mathrm{Mg}$ enrichment at the $\mathrm{MgO}$ surface. ${ }^{48}$ We surmise that by applying the correct deposition kinetics, or postgrowth annealing, the thermodynamics can favor certain percentage of Fe-Mg coordinated interface, as it is considered here in order to properly explain the exponential decrease of the averaged $\mathrm{Fe} \mathrm{mm}$ while increasing the $\mathrm{Fe}$ coverage, as depicted in Fig. 1. We stress that the phenomenon described here probably has an influence only on the first stages of the nucleation process.

The drop of the magnetic moment for the symmetric Fe-O case is also worth noting here (Fig. 1). The same sensitive dependence of the $\mathrm{mm}$ of the interfacial layer is reported for $\mathrm{Fe} / \mathrm{V} / \mathrm{MgO}$ and $\mathrm{Fe} / \mathrm{Co}$ heterostructures. ${ }^{49,50}$ In the following, we provide a qualitative understanding of this finding. On the one hand, our calculations suggest hybridization of $\mathrm{Fe}$ $3 d$ with $\mathrm{O} 2 p$ states, where the electronic structure of both $\mathrm{Fe}$ and $\mathrm{O}$ resemble the state of $\mathrm{FeO}$, which explains the formation of polarized oxygen-derived states usually found at the $\mathrm{Fe}-\mathrm{MgO}$ interface. ${ }^{21,40,51} \mathrm{In}$ this regard, $\mathrm{Fe}$ was previously calculated to induce a mm of $0.2 \mu_{\mathrm{B}}$ on the oxygen sites at the interface, ${ }^{52,53}$ while experimental results from Bowen et al. ${ }^{30}$ suggested induced moments no greater than $0.05 \mu_{\mathrm{B}}$. This trend is reproduced by our ab initio calculations, as can also be seen in Table I.
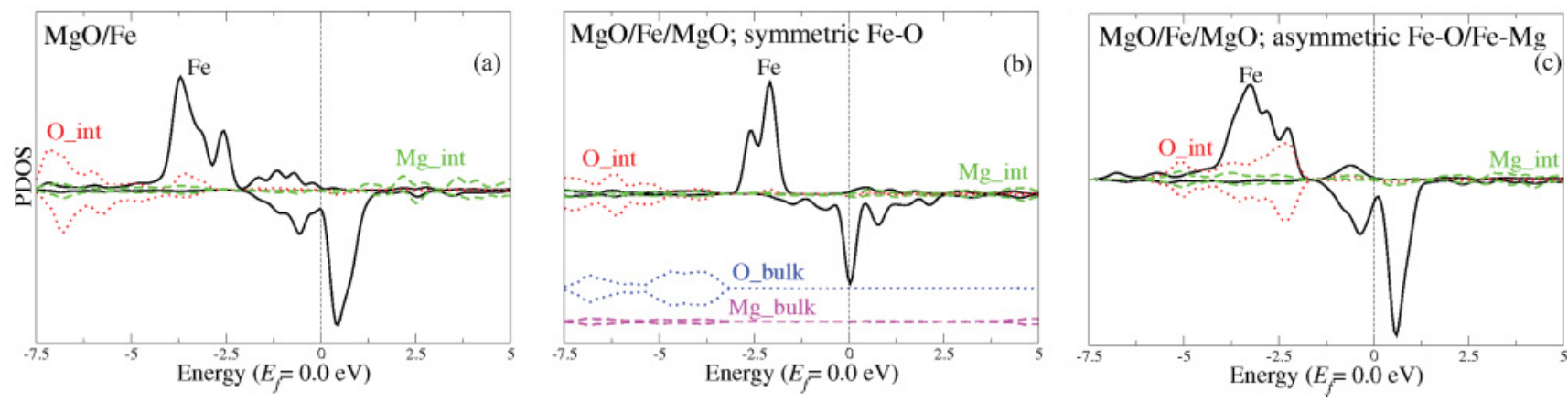

FIG. 3. (Color online) Projected DOS over the atoms at the interface (Fe, Mg_int, and O_int) and at inner layers (Mg_bulk, O_bulk) for different structures consisting of $0.5 \mathrm{ML} \mathrm{Fe}$ and $3 \mathrm{ML} \mathrm{MgO}$, where upwards (downwards) curves correspond to majority (minority) spins. The Fermi level $\left(E_{f}\right)$, depicted with dashed vertical lines, is set to zero for all plots. Solid, dotted, and dashed lines correspond to Fe, $\mathrm{O}$, and $\mathrm{Mg}$ atoms, respectively. (a) Corresponds to the $\mathrm{MgO} / \mathrm{Fe}$ structure with $\mathrm{Fe}-\mathrm{O}$ coordination, (b) to the conventional $\mathrm{MgO} / \mathrm{Fe} / \mathrm{MgO}$ structure with Fe atoms facing $\mathrm{O}$ ions, while in (c) the capping layer sits its $\mathrm{Mg}$ ions upon the iron. 
TABLE III. Magnetic moment (mm) for the interfacial atoms in $\mathrm{MgO}(3 \mathrm{ML}) / \mathrm{Fe} / \mathrm{FeO}(1 \mathrm{ML}) / \mathrm{MgO}(3 \mathrm{ML})$, stabilities for each structure, and averaged $\mathrm{mm} .5^{* *}$ corresponds to the case allowing for full relaxation of the atoms.

\begin{tabular}{|c|c|c|c|c|c|c|c|c|c|}
\hline & \multirow{2}{*}{$\begin{array}{l}\mathrm{Fe} \\
\mathrm{ML}\end{array}$} & \multicolumn{2}{|c|}{$\mathrm{MgO} \mid \mathrm{Fe}$} & \multicolumn{2}{|c|}{$\mathrm{Fe} \mid \mathrm{FeO}$} & \multicolumn{2}{|c|}{$\mathrm{FeO} \mid \mathrm{MgO}$} & \multirow{2}{*}{$\begin{array}{l}\mathrm{mm} \\
\left(\mu_{\mathrm{B}}\right)\end{array}$} & \multirow{2}{*}{$\begin{array}{c}\text { Stability } \\
(\mathrm{eV})\end{array}$} \\
\hline & & $\mathrm{O}$ & $\mathrm{Fe}$ & $\mathrm{Fe}$ & $\mathrm{Fe}(\mathrm{FeO})$ & $\mathrm{O}(\mathrm{FeO})$ & $\mathrm{O}(\mathrm{MgO})$ & & \\
\hline \multirow{5}{*}{ Symmetric Fe-O } & 0.5 & 0 & 2.69 & 2.69 & $3.59 / 3.56$ & $0.11 / 0.21$ & $0.02 / 0.03$ & 2.69 & 5.89 \\
\hline & 1 & 0 & $2.74 / 2.88$ & $2.74 / 2.88$ & $3.46 / 3.43$ & $0.13 / 0.17$ & $0.02 / 0.03$ & 2.81 & 6.19 \\
\hline & 3 & 0.03 & 3.08 & $2.98 / 2.99$ & $3.47 / 3.44$ & $0.19 / 0.19$ & $0.03 / 0.04$ & 2.96 & 11.77 \\
\hline & 5 & 0.03 & 3.07 & 2.91 & $3.43 / 3.46$ & 0.19 & $0.05 / 0.04$ & 2.86 & 19.38 \\
\hline & $5^{* *}$ & 0.03 & 2.86 & 2.69 & 3.40 & 0.20 & $0.05 / 0.04$ & 2.69 & 16.21 \\
\hline \multirow[t]{4}{*}{ Asymmetric $\mathrm{Fe}-\mathrm{O} / \mathrm{Fe}-\mathrm{Mg}$} & 0.5 & 0.05 & 2.69 & 2.69 & $3.54 / 3.52$ & $0.18 / 0.27$ & 0.00 & 2.69 & 6.79 \\
\hline & 1 & 0.02 & $2.61 / 2.59$ & $2.61 / 2.59$ & $3.38 / 3.43$ & 0.18 & 0.01 & 2.60 & 7.12 \\
\hline & 3 & 0.04 & 2.812 & 2.71 & $3.42 / 3.43$ & 0.21 & 0.01 & 2.75 & 12.42 \\
\hline & 5 & 0.03 & 3.06 & 2.91 & $3.43 / 3.45$ & 0.19 & 0.04 & 2.86 & 19.39 \\
\hline
\end{tabular}

We depict in Fig. 3 the projected density of states (PDOS) for the $\mathrm{MgO} / \mathrm{Fe}$ thin film and $\mathrm{MgO} / \mathrm{Fe} / \mathrm{MgO}$ structures showing $\mathrm{Fe}-\mathrm{O}$ and $\mathrm{Fe}-\mathrm{Mg}$ interfacial coordination. The PDOS for the "bulk-like" atoms (Mg_bulk, and O_bulk) is only included for the $\mathrm{MgO} / \mathrm{Fe} / \mathrm{MgO}$ structure with $\mathrm{Fe}-\mathrm{O}$ coordination, since we found it is similar among the three calculations, meaning the models employed provide a common bulk electronic structure as reference. Regarding the Fe contribution, we can see that Figs. 3(a) and 3(c) share qualitatively similar features, as a result of the charge smoothly extending into the vacuum region for the thin film case. ${ }^{17}$ On the other hand, the situation is very different in Fig. 3(b), where the Fermi level is located at the minority peak, and therefore the spin polarization (and $\mathrm{mm}$ ) is much lesser than in the former cases. We recognize a striking similarity in our results with those published by Shimabukuro et al. ${ }^{54}$ In this regard, the interfacial perpendicular anisotropy in $3 d$ transition metals adjacent to a $\mathrm{MgO}$ barrier has attracted considerable attention for its relevance to voltage-driven spintronics applications with low power consumption. ${ }^{55}$ Although not properly understood at this time, the close correlation between this perpendicular anisotropy and the drop in magnetization for overoxidized structures probably indicates that both have the very same origin, i.e., $p-d$ hybridization near Fermi level. Obviously, further work is required before firm conclusions can be drawn.

The previous results hold for perfectly epitaxial interfaces. However, the structure of interfaces in real samples appears to be significantly different from the ideal model used in our calculations. On the one hand, when growing $\mathrm{MgO}$ by evaporation or sputtering deposition, a gas containing a majority of atomic species is generated. ${ }^{22}$ Since $\mathrm{Mg}$ is very volatile and $\mathrm{O}$ rapidly sticks to the metal surface, ${ }^{56} \mathrm{FeO}$ is likely to result when depositing $\mathrm{MgO}$ onto $\mathrm{Fe}$. In this regard, spin-polarized experiments ${ }^{57}$ have previously highlighted the important role of stoichiometry in $\mathrm{MgO} / \mathrm{Fe}(001)$. Therefore, in order to complete the study and the comparison between experiments and theory, let us focus on the $\mathrm{MgO}(001) / \mathrm{Fe} / \mathrm{FeO} / \mathrm{MgO}$ structure where a $1 \mathrm{FeO}$ ML is intercalated between the Fe slab and the $\mathrm{MgO}$ capping layer. The results are shown in Table III. It is noteworthy that, unlike in the $\mathrm{MgO} / \mathrm{Fe} / \mathrm{MgO}$ structure, when inserting an $\mathrm{FeO}$ layer, the most stable coordination is $\mathrm{Fe}$ facing $\mathrm{O}$ at both interfaces, which also provides the larger $\mathrm{mm}$. It is also observed that the $\mathrm{mm}$ induced in the oxygen ions is negligible, except for those of the $\mathrm{FeO}$ layer, which often show two values due to the corrugation that arises from the interfacial charge displacements. It is interesting to see that the $\mathrm{Fe} \mathrm{mm}$ increases by increasing the $\mathrm{Fe}$ thickness for both the $\mathrm{MgO}$ (substrate) $/ \mathrm{Fe}$ and $\mathrm{Fe} / \mathrm{FeO}$ interfaces, reaching a value close to $3 \mu_{\mathrm{B}}$. Here, the role of the $\mathrm{FeO}$ layer is to support a rather constant and high value of $\mathrm{mm}$ through the entire $\mathrm{Fe}$ slab at least up to $5 \mathrm{ML}$. These findings indicate that the $\mathrm{MgO} / \mathrm{Fe} / \mathrm{FeO} / \mathrm{MgO}$ structure is a good candidate for the realization of double tunnel junctions, ${ }^{58,59}$ since the most stable interface configuration holds a relatively high $\mathrm{mm}$ value due to the incorporation of $\mathrm{FeO}$. To assess the validity of our results, we have also considered the relaxed structure of the supercell, meaning that the substrate lattice parameter is not fixed to the $\mathrm{MgO}$ constant. We observed that relaxation reduces the mm compared to the "constrained" $5 \mathrm{ML}$. This stems from the charge transfer at the interface, showing a charge reduction on $\mathrm{Fe}$ (electron donor) and a slight enhancement on the $\mathrm{O}$ (acceptor). This result is similar to that for the $\mathrm{MgO} / \mathrm{Fe} / \mathrm{MgO}$ structure with $\mathrm{Fe}-\mathrm{O}$ coordination, where relaxation at the interface results in smaller $\mathrm{mm}$.

In summary, we have performed a systematic study aiming at the understanding of the $\mathrm{mm}$ values of $\mathrm{MgO} / \mathrm{Fe} / \mathrm{MgO}$ structures. Results show that at the very first deposition stages for the capping layer, the most stable coordination is Fe facing $\mathrm{Mg}$, instead of the $\mathrm{Fe}-\mathrm{O}$, being the two classes of interfaces substantially different from each other. Mainly, the Fe-Mg coordination helps diminish the detrimental effect of the Fe-O bonding, where a small amount of covalency originates from the $3 d(\mathrm{Fe}) 2 p(\mathrm{O})$ hybridization (Fig. 3). Concomitant to this, the surface magnetization in Fe films is enhanced (Fig. 1). These results imply an interface model for magnetic tunnel junctions with asymmetric $\mathrm{Fe}-\mathrm{O} / \mathrm{MgO} / \mathrm{Mg}-\mathrm{Fe}$ layer stacking that is different from the ideal symmetric heterostructure, opening the path to a more accurate description and engineering of spintronic devices based on $\mathrm{MgO}$ barriers.

\section{ACKNOWLEDGMENTS}

C.M.B. is supported by the "Ramón y Cajal" program of Spain. The authors thank A. Cebollada, F. Illas, L. Giordano, and G. Pacchioni for stimulating discussions. 
*juan.beltran@uam.es

${ }^{1}$ W. H. Butler, X.-G. Zhang, T. C. Schulthess, and J. M. MacLaren, Phys. Rev. B 63, 054416 (2001).

${ }^{2}$ J. Mathon and A. Umerski, Phys. Rev. B 63, 220403(R) (2001).

${ }^{3}$ M. Bowen, V. Cross, F. Petroff, A. Fert, C. Martínez-Boubeta, J. L. Costa-Krämer, J. V. Anguita, A. Cebollada, F. Briones, J. M. de Teresa, L. Morellón, R. Ibarra, F. Güell, F. Peirò, and A. Cornet, Appl. Phys. Lett. 79, 1655 (2001).

${ }^{4}$ S. Yuasa, T. Nagahama, A. Fukushima, Y. Suzuki, and K. Ando, Nat. Mater. 3, 868 (2004).

${ }^{5}$ S. Ikeda, J. Hayakawa, Y. Ashizawa, Y. M. Lee, K. Miura, H. Hasegawa, M. Tsunoda, F. Matsukura, and H. Ohno, Appl. Phys. Lett. 93, 082508 (2008).

${ }^{6}$ M. Müller, F. Matthes, and C. M. Schneider, J. Appl. Phys. 101, 09G519 (2007).

${ }^{7}$ L. Plucinski, Y. Zhao, B. Sinkovic, and E. Vescovo, Phys. Rev. B 75, 214411 (2007).

${ }^{8}$ G. X. Miao, Y. J. Park, J. S. Moodera, M. Seibt, G. Eilers, and M. Münzenberg, Phys. Rev. Lett. 100, 246803 (2008).

${ }^{9}$ Y. Ke, K. Xia, and H. Guo, Phys. Rev. Lett. 105, 236801 (2010).

${ }^{10}$ J. M. Teixeira, J. Ventura, J. P. Araujo, J. B. Sousa, P. Wisniowski, S. Cardoso, and P. P. Freitas, Phys. Rev. Lett. 106, 196601 (2011).

${ }^{11}$ F. J. Palomares, C. Munuera, C. Martínez Boubeta, and A. Cebollada, J. Appl. Phys. 97, 036104 (2005)

${ }^{12}$ J. Goniakowski and C. Noguera, Interface Sci. 12, 93 (2004).

${ }^{13}$ T. Jaouen, G. Jézéquel, G. Delhaye, B. Lépine, P. Turban, and P. Schieffer, Appl. Phys. Lett. 97, 232104 (2010).

${ }^{14}$ T. Susaki, A. Makishima, and H. Hosono, Phys. Rev. B 83, 115435 (2011).

${ }^{15}$ D. Ricci, A. Bongiorno, G. Pacchioni, and U. Landman, Phys. Rev. Lett. 97, 036106 (2006).

${ }^{16}$ U. Martinez, G. Pacchioni, and F. Illas, J. Chem. Phys. 130, 184711 (2009).

${ }^{17}$ C. Li and A. J. Freeman, Phys. Rev. B 43, 780 (1991).

${ }^{18}$ T. Koyano, Y. Kuroiwa, E. Sita, N. Saegusa, K. Ohshima, and A. Tasaki, J. Appl. Phys. 64, 5763 (1988).

${ }^{19}$ M. Sicot, S. Andrieu, F. Bertran, and F. Fortuna, Phys. Rev. B 72, 144414 (2005).

${ }^{20}$ K. Mamiya, T. Koide, Y. Ishida, Y. Osafune, A. Fujimori, Y. Suzuki, T. Katayama, and S. Yuasa, Rad. Phys. Chem. 75, 1872 (2006).

${ }^{21}$ C. Martínez-Boubeta, L1. Balcells, C. Monty, P. Ordejon, and B. Martínez, Appl. Phys. Lett. 94, 062507 (2009).

${ }^{22}$ J. L. Vassent, A. Marty, B. Gilles, and C. Chatillon, J. Cryst. Growth 219, 444 (2000).

${ }^{23}$ H. Oh, S. B. Lee, J. Seo, H. G. Min, and J.-S. Kim, Appl. Phys. Lett. 82, 361 (2003).

${ }^{24}$ A. Iovan, S. Andersson, Yu. G. Naidyuk, A. Vedyaev, B. Dieny, and V. Korenivski, Nano Lett. 8, 805 (2008).

${ }^{25}$ C. Martinez-Boubeta, Ll. Balcells, and A. Cebollada, Appl. Phys. Lett. 88, 132511 (2006).

${ }^{26}$ C. Martínez-Boubeta, C. Clavero, J. M. García-Martín, G. Armelles, A. Cebollada, Ll. Balcells, J. L. Menéndez, F. Peiró, A. Cornet, and M. F. Toney, Phys. Rev. B 71, 014407 (2005).
${ }^{27}$ J. Orna, P. A. Algarabel, L. Morellón, J. A. Pardo, J. M. de Teresa, R. López Antón, F. Bartolomé, L. M. García, J. Bartolomé, J. C. Cezar, and A. Wildes, Phys. Rev. B 81, 144420 (2010).

${ }^{28}$ T. Haupricht, R. Sutarto, M. W. Haverkort, H. Ott, A. Tanaka, H. H. Hsieh, H.-J. Lin, C. T. Chen, Z. Hu, and L. H. Tjeng, Phys. Rev. B 82, 035120 (2010).

${ }^{29}$ V. M. Medel, J. U. Reveles, S. N. Khanna, V. Chauhan, P. Sen, and A. W. Castleman, PNAS 108, 10062 (2011).

${ }^{30}$ M. Bowen, V. Cros, H. Jaffrès, P. Bencok, F. Petroff, and N. B. Brookes, Phys. Rev. B 73, 012405 (2006).

${ }^{31}$ J. P. Perdew, K. Burke, and M. Ernzerhof, Phys. Rev. Lett. 77, 3865 (1996).

${ }^{32}$ J. M. Soler, E. Artacho, J. D. Gale, A. García, J. Junquera, P. Ordejón, and D. Sánchez-Portal, J. Phys.: Condens. Matter 14, 2745 (2002).

${ }^{33}$ J. I. Beltrán and M. C. Muñoz, Phys. Rev. B 78, 245417 (2008).

${ }^{34}$ O. Šipr, S. Bornemann, J. Minár, and H. Ebert, Phys. Rev. B 82, 174414 (2010)

${ }^{35}$ T. Kanaji, T. Kagotani, and S. Nagata, Thin Solid Films 32, 217 (1976).

${ }^{36}$ H. L. Meyerheim, R. Popescu, J. Kirschner, N. Jedrecy, M. SauvageSimkin, B. Heinrich, and R. Pinchaux, Phys. Rev. Lett. 87, 076102 (2001).

${ }^{37}$ M. C. Desjonquères, C. Barreteau, G. Autès, and D. Spanjaard, Phys. Rev. B 76, 024412 (2007).

${ }^{38}$ G.-X. Ge, Q. Jing, Z.-Q. Yang, and Y.-H. Luo, Chin. Phys. Lett. 26, 083101 (2009).

${ }^{39}$ K. Nakamura, T. Akiyama, T. Ito, M. Weinert, and A. J. Freeman, Phys. Rev. B 81, 220409(R) (2010).

${ }^{40}$ Y. Z. Wu, A. K. Schmid, and Z. Q. Qiu, Phys. Rev. Lett. 97, 217205 (2006).

${ }^{41}$ T. Shimada, Y. Ishii, and T. Kitamura, Phys. Rev. B 81, 134420 (2010).

${ }^{42}$ J. Goniakowski and C. Noguera, Surf. Sci. 323, 129 (1995).

${ }^{43}$ H. M. Benia, P. Myrach, N. Nilius, and H.-J. Freund, Surf. Sci. 604, 435 (2010).

${ }^{44}$ G. Wedler, C. M. Schneider, A. Trampert, and R. Koch, Phys. Rev. Lett. 93, 236101 (2004).

${ }^{45}$ B. D. Yu, Phys. Rev. B 71, 193403 (2005).

${ }^{46}$ K. Tsunekwa, D. D. Djayaprawira, M. Nagai, H. Maehara, S. Yamagata, N. Watanabe, S. Yuasa, Y. Suzuki, and K. Ando, Appl. Phys. Lett. 87, 072503 (2005).

${ }^{47}$ Y. Liu, A. N. Chiaramonti, D. K. Schreiber, H. Yang, S. S. P. Parkin, O. G. Heinonen, and A. K. Petford-Long, Phys. Rev. B 83, 165413 (2011).

${ }^{48}$ J. F. Anderson, M. Kuhn, U. Diebold, K. Shaw, P. Stoyanov, and D. Lind, Phys. Rev. B 56, 9902 (1997).

${ }^{49}$ X. Feng, O. Bengone, M. Alouani, I. Rungger, and S. Sanvito, Phys. Rev. B 79, 214432 (2009).

${ }^{50}$ B. Swinnen, J. Meersschaut, J. Dekoster, G. Langouche, S. Cottenier, S. Demuynck, and M. Rots, Phys. Rev. Lett. 78, 362 (1997).

${ }^{51}$ A. Cattoni, D. Petti, S. Brivio, M. Cantoni, R. Bertacco, and F. Ciccacci, Phys. Rev. B 80, 104437 (2009).

${ }^{52}$ E. Yu. Tsymbal, I. I. Oleinik, and D. G. Pettifor, J. Appl. Phys. 87, 5230 (2000).

${ }^{53}$ X.-G. Zhang, W. H. Butler, and Amrit Bandyopadhyay, Phys. Rev. B 68, 092402 (2003). 
${ }^{54}$ R. Shimabukuro, K. Nakamura, T. Akiyama, and T. Ito, Physica E 42, 1014 (2010).

${ }^{55}$ Y. Shiota, T. Nozaki, F. Bonell, S. Murakami, T. Shinjo, and Y. Suzuki, Nat. Mater. 11, 39 (2012).

${ }^{56}$ G. Geneste, J. Morillo, F. Finocchi, and M. Hayou, Surf. Sci. 601, 5616 (2007).
${ }^{57}$ M. Müller, F. Matthes, and C. M. Schneider, EPL 80, 17007 (2007).

${ }^{58}$ T. Nozaki, A. Hirohata, N. Tezuka, S. Sugimoto, and K. Inomata, Appl. Phys. Lett. 86, 082501 (2005).

${ }^{59}$ D. Herranz, F. G. Aliev, C. Tiusan, M. Hehn, V. K. Dugaev, and J. Barnas, Phys. Rev. Lett. 105, 047207 (2010). 